\title{
Nurturing Internal Supply Chain Integration
}

\author{
Chuda Basnet \\ Department of Management Systems \\ The University of Waikato, Hamilton, New Zealand \\ E-mail: chuda@waikato.ac.nz \\ Joel Wisner \\ Department of Management \\ University of Nevada, Las Vegas, Las Vegas, Nevada, USA \\ E-mail: joel.wisner@unlv.edu
}

\begin{abstract}
A firm's internal supply chain refers to the specific value-creating functions within the organisation, such as production, sales and distribution. Previous research has shown that these functions need to work together to achieve high levels of firm performance. However, the means to achieve this integration of internal supply chain functions have not received much attention in the current literature. In this paper, we review the published literature on internal supply chain integration and report on empirical research, which we conducted to test various antecedents of integration. Results from our survey indicate that line managers are able to improve functional integration by fostering a positive attitude towards other departments. Integration appears also to be enhanced by making departments jointly accountable for achieving company goals.
\end{abstract}

Keywords: cross functional interfaces, supply chain management, teams (internal/external coordination), integration.

\section{Introduction}

A firm's internal supply chain refers to the chain of value-creating activities or functions (see Figure 1) within the company that conclude with providing a product or service to the customer. Integration of these functions involves holistic performance of activities across departmental boundaries. A wellintegrated internal supply chain should result in higher levels of customer service and other company performance metrics.

Much of the current research literature focuses on the performance benefits of a well-integrated internal supply chain. Research evidence shows that internal functional integration improves a company's performance, and can lead to successful external supply chain integration. However, the research on enhancement of internal integration is still at an early stage. Some of this work is conceptual (Lunn, 1997; van Hoek et al., 2008) while other literature is devoted to theory-building (Pagell, 2004). The research on theory-testing is quite limited (Murphy and Poist, 1992; Mollenkopf et al., 2000; Hansen and Nohria, 2004). This paper attempts to contribute to this last stream of research. In this paper the steps a firm can take to improve its internal integration were identified from the existing literature. A survey was then designed and used to measure the effect of these steps on the integration achieved. This research has both academic and practical motivations - the academic motivation is the paucity of literature in this area and the practical motivation is that practitioners need guidance on effective interventions to improve a company's internal integration. 
Figure 1. Internal Supply Chain Integration

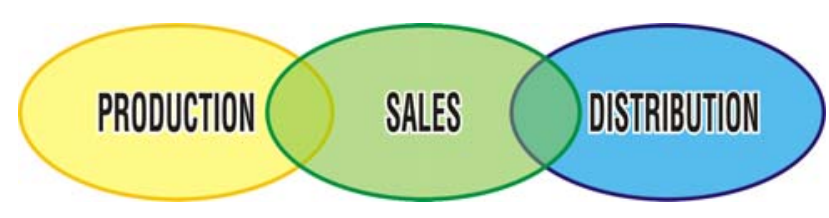

The contribution of this paper is the empirical testing of theories linking integration antecedents to actual integration levels achieved. We posit 12 hypotheses that relate organisational interventions to enhanced internal integration. A survey was carried out to test the hypotheses. The survey data was analysed using multiple regression. Our findings concur with some previous results, but also raise some questions about other widely accepted beliefs.

The next sections present a literature review, a statement of the research objective, and a description of the research methodology, followed by a statistical analysis of the collected survey data. In the final section, the findings are discussed and some further research directions are suggested. Unless indicated otherwise by the context, the word "integration" is used to mean internal supply chain integration throughout the paper.

\section{Literature Review}

In one of the early papers addressing supply chain management, Lambert et al. (1998) developed a general model of supply chain management, applicable to any enterprise, based on the following definition:

\footnotetext{
Supply chain management is the integration of key business processes from end user to original suppliers that provides products, services, and information that add value for customers and other stakeholders.
}

As can be seen here, integration of key valueproducing processes plays a very important role in successful supply chain management. In one of the earliest discussions of internal integration, Lawrence and Lorsch (1967) defined integration as "the quality of the state of collaboration that exists among departments that are required to achieve unity of effort by the demands of the environment." Additionally, it is generally accepted that supply chain integration evolves in the following stages (Stevens, 1989): functional integration, whose focus is intrafunctional, followed by internal supply chain integration, whose focus is inter-functional, and finally external supply chain integration, whose focus is interfirm. Giménez, (2004) supported this evolution in her exploratory study of supply chain integration. Stank et al., (2001) also supported the link between internal and external integration. Even though studies of internal integration are relatively new in the supply chain context (Giménez, 2004; Giménez and Ventura, 2003; Pagell, 2004), there have been many earlier studies in the area of inter-functional integration in the contexts of new product development and the productionmarketing interface (e.g. Calantone et al., 2002; Kahn, 1996; Kahn and Mentzer, 1996; Mollenkopf et al., 2000; Stank et al., 1999).

Even as this research on integration continues, there is no clear consensus on the definition of integration. Researchers have attached various phrases to the construct of integration, such as: communication, interaction, coordination, collaboration, harmony, adherence to the "integrated logistics" concept, cooperation, interfacing, and consultation. Thus, within the context of this research, a basic requirement for integration is that the independent functions within an organization work together. Supply chain integration is often justified on the basis that the entities of a supply chain should work holistically, trying to optimise a common outcome rather than each entity optimising its own interests. Indeed, unity of purpose is essential for any definition of integration. Thus, for this research, a simple minimal definition of integration is adoptedworking together for the benefit of the company.

Most of the studies on internal integration have sought to determine the performance benefits of integration. Chen et al., (2007) for instance, found that marketing-logistics collaborative activities led to firmwide integration, which in turn led to performance. Ellinger (2000) also investigated marketing-logistics collaboration and posited that "evaluation and reward system", "cross-functional collaboration", "effective inter-departmental relations" and "distribution service performance" were serially linked. This linkage was supported using a survey and regression analysis. Giménez and Ventura (2003) tested the 
effects of internal integration and external integration on performance, using a survey and structural equation modelling. They found that both had a positive effect on performance. Kahn and Mentzer, (1998) sought to separately identify the benefits of communication and collaboration on performance in the context of marketing's integration with other departments. They found significant benefits for collaboration, but not for communication. O'LearyKelly and Flores (2002) studied the effect of mediating variables on the relationship between integration and performance using a survey and regression analysis. They found that the benefits of production-marketing integration were not always worth the cost of such integration. They concluded that the cost of integration could only be justified by examining the internal and external environments faced by a firm.

In recent years, there have been studies of the relationships between internal integration, external (customer and supplier) integration, and performance. Droge et al., (2004) considered two components of integration: internal integration in the context of design - process integration, and external integration (supplier as well as customer). They sought to determine the effect of these constructs on time-based performance and overall firm performance. Using a survey of automotive suppliers and regression analysis, they found that both integration practices had direct effects on overall firm performance as well as an indirect effect on time-based performance. The two integration practices also had a direct "synergistic" effect on overall firm performance. Barratt and Barratt (2011) examined the relationship between internal and external supply chain linkages through a case study and proposed hypotheses on how information flows across these linkages. Flynn et al. (2010) carried out a survey of Hong Kong manufacturers and used hierarchical regression analysis to find that internal integration was positively related to business and operational performance. Customer integration was directly related only to operational performance, while supplier integration was not directly related to either performance measures. Narayanan et al., (2011) conducted a survey and path analysis to find that internal and external process integration mediated the impact of their antecedents on the performance of business process outsourcing companies. Childerhouse and Towill (2011) found that as the breadth of supply chain integration increased, performance of supply chains increased. Wong and Boon-itt (2011) investigated the role environmental uncertainty played in the effects of internal, supplier, and customer integration on performance measures of delivery, cost, quality, and flexibility. All three dimensions of integration had positive effects on performance measures. Increased uncertainty highlighted the relationship of external integration to delivery and flexibility performance and the relationship of internal integration to product quality and cost. Thus, new research has explored the relationship between internal and external integration, and for the most part, these linkages lead to performance benefits for the organization. This observation supports the need to study how to nurture internal integration, as discussed below.

A smaller stream of research is focused on the antecedents of internal integration. Calantone et al. (2002) used a survey and structural equation modelling to find that marketing's knowledge of manufacturing and manufacturing's evaluation of marketing communication both had positive relationships with marketing-manufacturing integration. Hausman et al. (2002) proposed a model linking antecedents to manufacturing-marketing integration, and then integration to profits. They found using a survey that the strategic importance of both departments was positively related to integration, and integration was related to profits. This suggested that top management should strive to view both marketing and manufacturing as key contributors to a firm's competitive strategy in order to boost integration (and hence profits). Pagell (2004) conducted case studies to determine the factors fostering or inhibiting internal integration in firms. His focus was on the integration of the production, logistics, and purchasing functions. He identified the constructs influencing integration as structure, culture, facility layout, job rotation and crossfunctional teams. Mollenkopf et al. (2000) conducted a survey in New Zealand to verify their model linking antecedents to inter-functional integration. Regression analysis showed that including integration in strategic plans helped in fostering integration. Cross-training helped as well, but reward systems (such as remuneration, promotion, incentives) did not prove significantly effective in this research.

As discussed above, a significant amount of research has been conducted on the performance benefits of both internal and external integration, 
which by and large has shown that integration provides performance benefits to the organization. A complementary theme of research seeks to identify the antecedents of integration, with the ultimate goal of normatively suggesting to management what it can do to foster integration. Many such suggestions have been made including changing the culture, job rotation, increasing knowledge of one another, incentive schemes, and adjusting top management's attitude. Studies empirically connecting these antecedents to improved internal integration however, have been quite limited. Antecedents of integration are discussed below, along with the accompanying research hypotheses.

\subsection{Job rotation}

Moving employees along the internal supply chain enhances their holistic understanding of the entire supply chain. Additionally, this should enhance relationships, communication, and integration among the various functions. The use of job rotation is strongly supported in lean management and product development literature. Pagell, (2004) for example, in his exploratory case studies, proposed a link between job rotation and communication in firms. Current literature suggests the following hypothesis.

\section{H1: The practice of job rotation enhances integration.}

\subsection{Performance incentives for managers}

In many organisations the performance of managers is assessed and rewarded on the basis of achieving functional goals. Thus, production managers are rewarded for achieving cost targets, and distribution managers are rewarded on their firms' delivery performances. While these goals might seem sensible, when assessments and rewards are not based on company performance, such as profits or customer retention, the functional goals may result in antagonism among the functions. Mollenkopf et al. (2000) did not find evidence for a link between reward systems and integration, but their focus was integration-based rewards rather than company performance-based rewards. Pagell (2004) also found support for tying managers' rewards to company goals. Thus, the following hypothesis is proposed.

H2: Linking the salaries of managers to company goals instead of functional goals, leads to integration.

\subsection{Top management emphasis on integration}

Leadership influences behaviour in organisations. It can be expected that if top managers emphasise the importance of integration to functional departments, the departments will follow suit. The importance of top management support has been stressed in the change management literature. Mollenkopf et al. (2000) studied marketing and logistics integration, and found that top management support played a significant part in the integration achieved. This leads to the following hypothesis.

H3: The importance placed by top management on integration will be reflected by the level of integration in a company.

\subsection{Line managers' encouragement of positive attitudes between departments}

At a lower level, line managers also have a role to play in fostering integrative behaviours among their staff. It can be expected that if the line managers are seen to fight turf battles and have negative attitudes towards other departments, the subordinates will emulate this behaviour. This concept gives rise to the following hypothesis.

H4: The level of integration in a firm is influenced by the line managers' encouragement of positive worker attitudes.

\subsection{Co-location}

The use of co-location is commonly seen in lean management where supplier representatives and customers locate together to enhance relationships and supply chain integration. For example, Cousineau et al. (2004) found co-location to be an enabler for supplier integration in a large manufacturing firm. The same concept can be applied internally. When the internal supply chain functions are located together, problems can be easily sorted out, and there is a better opportunity for interactions among the functions. The following hypothesis is thus proposed.

H5: Co-location of internal supply chain functions enhances integration among the functions. 


\subsection{Joint accountability}

By holding disparate functional managers jointly accountable for company goals, the managers may be expected to perform in a more integrated manner. Joint accountability for outcomes, including mutual rewards for successes and mutual responsibility for failures, was one of the themes that emerged from the interviews conducted by Ellinger et al. (2006). The following hypothesis is thus proposed for testing.

H6: Joint accountability promotes functional integration.

\subsection{Employee incentives}

If employees in a company are rewarded for satisfying customers, it may be expected that they will jointly focus their efforts on customer satisfaction, and will integrate their activities correspondingly. Murphy and Poist (1992) suggested establishing a system of incentives to share the rewards and risks of cooperative functional efforts. Van Hoek and Mitchell (2006) also suggested aligning the goals of functions and linking them to incentives in order to foster internal integration. Thus the following hypothesis is proposed.

H7: Rewarding employees for acting in the customer's interest will raise the level of internal supply chain integration.

\subsection{Company-wide consensus on strategy}

By establishing company-wide consensus on the goals and objectives of a company, top management can expect that the company will work together to achieve those goals. Pagell (2004) for example, proposed that the level of strategic consensus was an indicator of internal integration. This supports the following hypothesis.

H8: The extent of consensus on company strategy influences internal integration.

\subsection{Top management emphasis on the culture of collaboration}

Collaboration between functional departments is a cultural behaviour. It is the responsibility of top management in a company to instil a positive, supportive culture while discouraging activities which can negatively impact culture in their organisation. The extent to which top management emphasises collaboration by their words and actions should have an effect on integration. Kahn and Mentzer (1994) stressed the importance of norms in the development of marketing orientations. In a more recent article, Soti et al. (2010) surveyed Indian manufacturing companies and found top management leadership and organizational culture to be critical success factors for Six Sigma, a companywide quality improvement initiative. We propose the following hypothesis.

H9: The level of integration will be affected by the emphasis top management places on the culture of collaboration.

\subsection{Employee training regarding other departments}

When employees are solely focused on their own specialty, they may not fully understand the needs of others in different departments within their company. Training people in other internal supply chain functions and procedures should encourage worker collaboration across departments. While the objective of job rotation is also to enhance employee understanding of other departments, we refer here to formal employee training (without relocation) to achieve the same goal. The importance of inter-organizational training to improve integration for example, was stressed by Daugherty et al. (1996). Aggarwal and Singh (2004) also suggested in their study of 22 Indian firms, that interdepartmental training encouraged interdepartmental connectedness. The following hypothesis is proposed for testing.

H10: Training employees regarding other departments increases the level of integration.

\subsection{Informal interactions}

Informal interactions outside the work environment, such as get-togethers and sporting activities are helpful in building closer relationships among members across functional departments. Hansen and Nohria (2004) and Griffin and Hauser (1996) have suggested informal networks as a means to 
overcome the barriers to inter-functional collaboration. The following hypothesis is thus proposed.

\section{H11: Informal interactions among disparate functional groups increases integration.}

\subsection{Enterprise-wide computer systems}

Outdated "legacy" systems that do not support a company-wide information perspective have been blamed for poor integration (Daugherty et al., 1996). In their survey, respondents associated the integrated logistics concept strongly with information systems. Modern enterprise resource planning (ERP) software applications provide complete information integration across a company and thus can be expected to serve as a catalyst for internal supply chain integration. We propose the following hypothesis.

\section{H12: Enterprise-wide computer systems foster integration.}

Figure 2 presents the model adopted for our research. The twelve antecedents or interventions to improve integration are based on our hypotheses above, and are shown in the model. The interventions have been classified according to their hierarchical level within the organisation.

The next section discusses the research methodology, followed by an analysis and discussion of the results along with conclusions and future research directions.

\section{Research Methodology}

\subsection{Research objective}

The goal of this research was to test the various hypotheses on internal supply chain integration as presented in the previous section. Since this is a theory-testing research, a survey-based quantitative methodology was selected.

\subsection{The survey}

A mail questionnaire and a postage-free return envelope were sent to 999 of the largest manufacturing firms in New Zealand in October 2010. These firms were identified through a commercial database of businesses, called KOMPASS. The selected firms were the largest manufacturers in New

Figure 2. Antecedents of Internal Integration

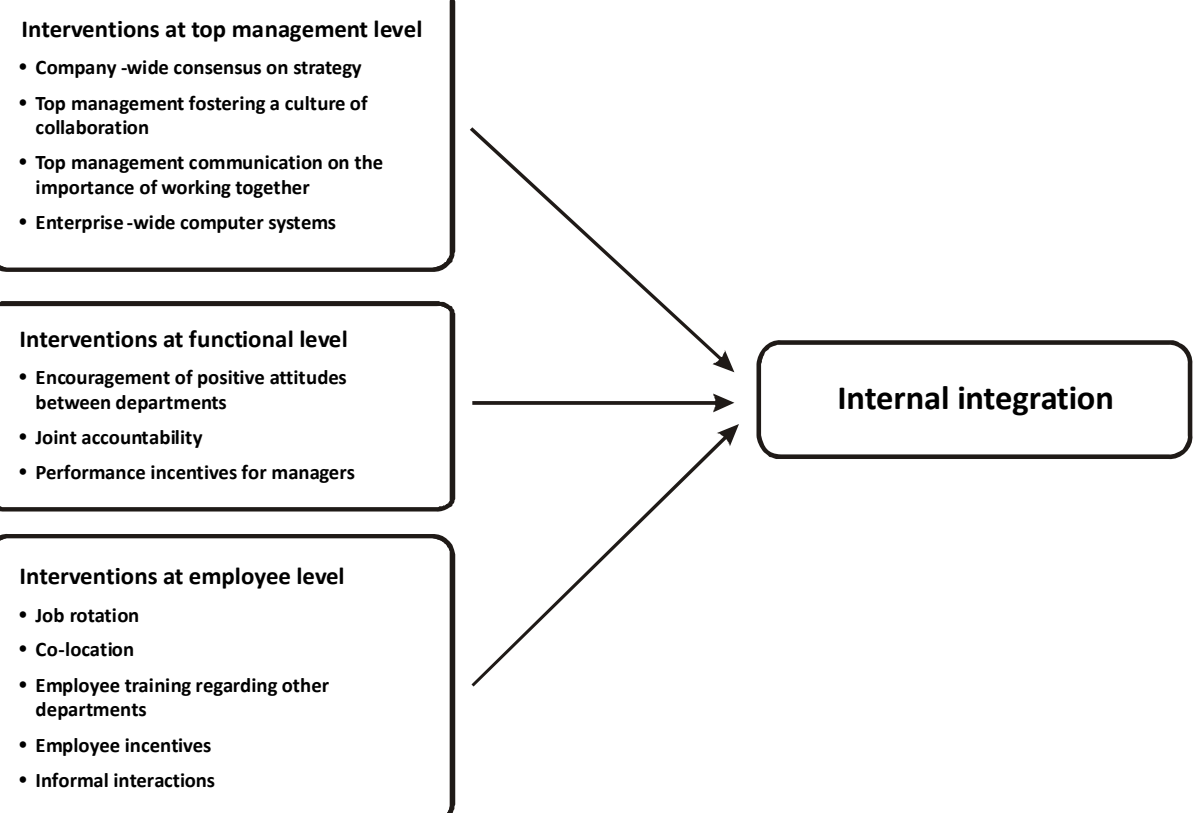


Zealand with respect to the number of employees, the rationale being that the larger firms were likely to have distinct departments in their internal supply chains in various stages of integration. The survey questionnaire is included in Appendix 1.

The survey was mailed to either the general managers (or their equivalent) or to a top executive in production, sales, or distribution in order to ensure that the respondents were knowledgeable about the state of integration in their companies. All the items in the survey used a 7-point Likert scale ( $1=$ Strongly disagree, $4=$ Neutral, $7=$ Strongly agree).

The questionnaire was accompanied by a cover letter highlighting the reasons for the research, assuring confidentiality, and promising a summary of the research report. A serial number was included for follow-up. After one month, when the flow of responses had started to dwindle, a reminder was sent with another copy of the questionnaire and another postage-free return envelope. When the responses had stopped, there was a tally of 273 usable responses. This was a response rate of 27 percent, which was considered quite high for this type of survey.

The number of employees in the respondent firms is shown in Table 1. While these firms represent large manufacturing firms in New Zealand, by international standards most respondents would be classified as small to medium sized firms.

Table 1. Demographics of the sample

\begin{tabular}{|c|c|}
\hline Number of employees & Frequency \\
\hline Up to 20 & 6 \\
$21-50$ & 74 \\
$51-100$ & 85 \\
$101-150$ & 45 \\
$151-200$ & 12 \\
More than 200 & 50 \\
\hline Total & 273 \\
\hline
\end{tabular}

The 273 usable responses were analysed using commercial software (SPSS), as detailed in the next section.

\section{Analysis and Results}

\subsection{Non-response bias test}

Even though the response rate was quite high, the question of non-response bias was still a potential issue. Conceivably, the firms not responding could be different from the respondents; which would lead to the conclusion that the sample does not actually represent the entire population. Assuming that late responders were similar to non-responders, responses from early and late groups were compared. The first 25 percent of the sample collected was used as the early group and these were compared to the last 25 percent of the sample collected. The hypothesis could not be rejected that the means of each of the 29 item-responses was the same for the two groups, using a two-tailed t-test at $p=0.05$. Similarly, a Pearson Chi square test on an organisational characteristic (number of workers) rejected the null hypothesis that there was an association between organisation size and tardiness in response $(p=0.848)$. These tests gave confidence that the non-response bias in this study was minimal.

\subsection{Measurement of integration levels}

The respondents were presented with a 16-item instrument to measure their firm's integration level. An overall measure (criterion) of integration as "working together for the benefit of the company" (Q17) was also included on the survey. After data collection, Pearson correlation coefficients between all the different measures were examined. None of the correlations were found to be very high (highest $=0.715)$, suggesting that there was no multicollinearity in the data. Item to sum-of-items correlations were high (0.523 to 0.787). All the correlations were statistically significant at $p=0.001$. This gave confidence that the items measured the same construct. However, the correlation of Q6 (see Appendix 1) with the criterion Q17 was particularly low (0.307). For this reason, item Q6 was dropped from further analysis. Cronbach's alpha for the resulting 15-item scale (Q1-Q16, except Q6) for the measurement of integration was 0.94 , which indicated a high level of scale reliability. 


\subsection{Hypothesis testing}

Internal integration level, as measured by the average of the 15-item scale mentioned above, was treated as a dependent variable for the purpose of hypothesis-testing in this research. The 12 hypotheses discussed in the literature review are associated with one independent variable each, measured by a single item in the survey (see Appendix 1). All of the 12 independent variables (except the last) were measured by a 7-point Likert scale, and were treated as rational variables. The last survey item asked for the number of years since implementing enterprise-wide computer systems (ERP). It is commonly accepted that it takes many years for the full effects of ERP systems to take effect. Using a cut-off period of 3 years, the last independent variable was a "dummy" variable: coded as 1 when the number of years of ERP adoption was 3 or more, and 0 otherwise. A multiple regression analysis was then carried out with 12 independent variables and one dependent variable (integration level).

\subsection{Statistical results}

The overall model had a coefficient of determination $\left(\mathrm{R}^{2}\right)$ of 0.616 . While this finding is considered satisfactory, a fairly high percentage of the variation of the integration measure was not explained by the regression model, which suggests that there may be other antecedents of integration that were not included in the research. However, the analysis of variance (ANOVA) showed that the model had a high significance $(p<0.001)$, indicating that at least one or more of the independent variables had a significant effect on integration. The adjusted $R^{2}$ was 0.598 , which is very close to $R^{2}$; this indicates that the model can be generalized from the sample to a wider population.

\subsection{Regression coefficients}

The coefficients of regression are shown in Table 2. The significant $(\mathrm{p}<0.05)$ predictor variables were: Q21 (Line managers' encouragement of positive attitudes between departments), Q22 (Co-location), and Q23 (Joint accountability). Even though not significant at the

Table 2. Coefficients of Regression

\begin{tabular}{|c|c|c|c|c|c|c|c|c|}
\hline & & \multicolumn{2}{|c|}{$\begin{array}{l}\text { Unstandardized } \\
\text { Coefficients }\end{array}$} & \multirow{2}{*}{$\begin{array}{c}\begin{array}{c}\text { Standardized } \\
\text { Coefficients }\end{array} \\
\text { Beta }\end{array}$} & \multirow{2}{*}{$\boldsymbol{T}$} & \multirow{2}{*}{ Sig. } & \multicolumn{2}{|c|}{ Collinearity Statistics } \\
\hline & & B & $\begin{array}{l}\text { Std. } \\
\text { Error }\end{array}$ & & & & Tolerance & VIF \\
\hline Constant & & 1.732 & .208 & & 8.347 & .000 & & \\
\hline Q18 & Job rotation & .044 & .024 & .078 & 1.850 & .065 & .842 & 1.188 \\
\hline Q19 & $\begin{array}{l}\text { Managers' salaries based on company-wide } \\
\text { performance }\end{array}$ & -.022 & .023 & -.041 & -.946 & .345 & .780 & 1.282 \\
\hline Q20 & $\begin{array}{l}\text { Top management communication on } \\
\text { the importance of working together }\end{array}$ & .061 & .038 & .087 & 1.586 & .114 & .500 & 1.999 \\
\hline Q21 & $\begin{array}{l}\text { Managers fostering positive attitude between } \\
\text { departments }\end{array}$ & .366 & .045 & .451 & 8.136 & .000 & .486 & 2.057 \\
\hline Q22 & Co-location & .058 & .023 & .110 & 2.513 & .013 & .776 & 1.289 \\
\hline Q23 & Departments' joint accountability for results & .063 & .029 & .112 & 2.209 & .028 & .578 & 1.731 \\
\hline Q24 & Employee incentives for customer satisfaction & -.001 & .030 & -.002 & -.048 & .962 & .586 & 1.707 \\
\hline Q25 & $\begin{array}{l}\text { Top management developing company-wide } \\
\text { consensus on strategy }\end{array}$ & .024 & .033 & .041 & .746 & .456 & .486 & 2.056 \\
\hline Q26 & $\begin{array}{l}\text { Top management fostering a culture of } \\
\text { collaboration }\end{array}$ & .065 & .041 & .102 & 1.584 & .114 & .360 & 2.775 \\
\hline Q27 & $\begin{array}{l}\text { Employee-training regarding their own and other } \\
\text { departments }\end{array}$ & .057 & .032 & .091 & 1.770 & .078 & .561 & 1.781 \\
\hline Q28 & $\begin{array}{l}\text { Informal interactions (picnics, sports events) } \\
\text { between employees across departments }\end{array}$ & -.010 & .026 & -.018 & -.381 & .704 & .707 & 1.415 \\
\hline ERP & Company-wide (ERP) computer system & .017 & .069 & .009 & .240 & .811 & .964 & 1.037 \\
\hline
\end{tabular}


Table 3. Collinearity Diagnostics

\begin{tabular}{|c|c|c|c|c|c|c|c|c|c|c|c|c|c|c|c|}
\hline \multirow{2}{*}{$\begin{array}{l}\text { Dimen- } \\
\text { sion }\end{array}$} & \multirow{2}{*}{$\begin{array}{l}\text { Eigen- } \\
\text { value }\end{array}$} & \multirow{2}{*}{$\begin{array}{l}\text { Condition } \\
\text { Index }\end{array}$} & \multicolumn{13}{|c|}{ Condition Index } \\
\hline & & & Constant & Q18 & Q19 & Q20 & Q21 & Q22 & Q23 & Q24 & Q25 & Q26 & Q27 & Q28 & ERP \\
\hline 1 & 12.012 & 1.000 & .00 & .00 & .00 & .00 & .00 & .00 & .00 & .00 & .00 & .00 & .00 & .00 & .00 \\
\hline 2 & .399 & 5.490 & .00 & .00 & .00 & .00 & .00 & .00 & .00 & .00 & .00 & .00 & .00 & .00 & .88 \\
\hline 3 & .118 & 10.092 & .00 & .84 & .04 & .00 & .00 & .01 & .00 & .00 & .01 & .00 & .00 & .02 & .00 \\
\hline 4 & .105 & 10.721 & .00 & .07 & .42 & .00 & .00 & .19 & .04 & .03 & .00 & .00 & .00 & .00 & .00 \\
\hline 5 & .082 & 12.104 & .00 & .03 & .32 & .00 & .00 & .33 & .00 & .00 & .04 & .00 & .03 & .12 & .00 \\
\hline 6 & .060 & 14.157 & .00 & .00 & .02 & .02 & .01 & .03 & .00 & .00 & .09 & .04 & .00 & .66 & .00 \\
\hline 7 & .052 & 15.151 & .04 & .02 & .03 & .01 & .01 & .02 & .25 & .47 & .03 & .00 & .01 & .07 & .04 \\
\hline 8 & .045 & 16.259 & .01 & .01 & .08 & .00 & .00 & .12 & .62 & .31 & .03 & .00 & .02 & .00 & .01 \\
\hline 9 & .038 & 17.836 & .00 & .01 & .05 & .00 & .00 & .00 & .00 & .12 & .03 & .00 & .89 & .08 & .01 \\
\hline 10 & .036 & 18.329 & .26 & .00 & .00 & .03 & .05 & .28 & .02 & .00 & .28 & .03 & .00 & .01 & .01 \\
\hline 11 & .022 & 23.443 & .13 & .00 & .00 & .00 & .07 & .01 & .00 & .05 & .41 & .52 & .03 & .04 & .02 \\
\hline 12 & .019 & 25.035 & .19 & .01 & .03 & .92 & .04 & .00 & .01 & .00 & .05 & .03 & .00 & .00 & .02 \\
\hline 13 & .013 & 30.860 & .37 & .00 & .00 & .01 & .81 & .01 & .04 & .01 & .03 & .36 & .01 & .00 & .01 \\
\hline
\end{tabular}

$\mathrm{p}<0.05$ level, the effect of the variables Q18 (Job rotation) and Q27 (Employee training regarding other departments) were significant at the $\mathrm{p}<0.10$ level.

\subsection{Multicollinearity}

The variable inflation factors (VIF) in Table 2 are all less than 10, indicating that multicollinearity was not a serious problem in this regression model. The collinearity diagnostics produced by SPSS are shown in Table 3. All variance proportions more than 0.4 are highlighted.

The only dimension with two variance proportions more than 0.4 was \#11. This indicated that Q25 and Q26 might have slight collinearity between them. However these two variables had a simple Pearson Correlation coefficient of 0.657 . This was not considered high enough $(>0.9)$ to cause concern.

\subsection{Residuals}

The Durbin-Watson statistic was 2.101, which was close to the ideal value of 2.0. Thus there was no reason to doubt the normality of the residuals.

\subsection{Multiple regression with factors of integration}

An exploratory factor analysis of the 15 scale-items for measuring integration revealed three components of integration:
Coordination (which loaded on Q10, Q12, Q13, Q14, Q15, and Q16)

Communication (which loaded on Q1, Q2, Q3, Q4, Q5, and Q7)

Affective relationship (which loaded on Q5, Q8, Q9, and Q11)

To discover how the antecedent variables affected the above components of integration, multiple regression analysis was carried out with each of the three components as the dependent variable and the antecedent variables as independent variables. All three regression models were significant at the $p<$ 0.001 level. Table 4 summarises the results of the multiple regression analysis. While the components in Table 4 refer to the components of integration mentioned above, the overall integration measure refers to the 15-item measure of integration discussed in section 4.2 and used throughout this research.

\subsection{Multiple regression with subgroups}

Further multiple regression analyses were carried out across two different sub-groupings. The first subgrouping was based on number of employees. Companies with less than 100 employees were coded as small companies, while the rest were coded as large companies. The second sub-grouping was based on the responding companies' production policies: maketo-order or make-to-stock. The analysis of variance 
Table 4. Regression Coefficients and Their Significance for Components of Integration

\begin{tabular}{|c|c|c|c|c|}
\hline \multirow{2}{*}{ Antecedent } & \multicolumn{3}{|c|}{ Components of integration } & \multirow{2}{*}{$\begin{array}{c}\text { Overall } \\
\text { integration } \\
\text { measure }\end{array}$} \\
\hline & Coordination & Communication & $\begin{array}{l}\text { Affective } \\
\text { relationship }\end{array}$ & \\
\hline Job rotation & $\begin{array}{l}0.087 \\
\text { Strong }\end{array}$ & & & $\begin{array}{c}0.044 \\
\text { Mild }\end{array}$ \\
\hline \multicolumn{5}{|l|}{ Managers' salaries based on company-wide performance } \\
\hline Top management communication on the importance of working together & & $\begin{array}{l}0.091 \\
\text { Strong }\end{array}$ & & \\
\hline Managers fostering positive attitude between departments & $\begin{array}{l}0.423 \\
\text { Strong }\end{array}$ & $\begin{array}{l}0.329 \\
\text { Strong }\end{array}$ & $\begin{array}{l}0.290 \\
\text { Strong }\end{array}$ & $\begin{array}{l}0.366 \\
\text { Strong }\end{array}$ \\
\hline Co-location & $\begin{array}{l}0.079 \\
\text { Strong }\end{array}$ & & $\begin{array}{l}0.068 \\
\text { Strong }\end{array}$ & $\begin{array}{ll}0.058 \\
\text { Strong }\end{array}$ \\
\hline Departments' joint accountability for results & $\begin{array}{l}0.084 \\
\text { Strong }\end{array}$ & $\begin{array}{l}0.058 \\
\text { Mild }\end{array}$ & & $\begin{array}{l}0.063 \\
\text { Strong }\end{array}$ \\
\hline \multicolumn{5}{|l|}{ Employee incentives for customer satisfaction } \\
\hline \multicolumn{5}{|l|}{ Top management developing company-wide consensus on strategy } \\
\hline \multicolumn{5}{|l|}{ Top management fostering a culture of collaboration } \\
\hline Employee-training regarding their own and other departments & & $\begin{array}{l}0.074 \\
\text { Mild }\end{array}$ & & $\begin{array}{l}0.057 \\
\text { Mild }\end{array}$ \\
\hline \multicolumn{5}{|l|}{$\begin{array}{l}\text { Informal interactions (picnics, sports events) between employees across } \\
\text { departments }\end{array}$} \\
\hline Company-wide (ERP) computer system & & & & \\
\hline
\end{tabular}

Strong indicates a significance of $p<0.05$; Mild indicates $p<=0.10$; Entry is blank when $p>0.10$

\section{Table 5. Regression coefficients and their signifficance for subgroups}

\begin{tabular}{|c|c|c|c|c|}
\hline \multirow[b]{2}{*}{ Antecedent } & \multicolumn{2}{|c|}{ Company size } & \multicolumn{2}{|c|}{ Production Policy } \\
\hline & $\begin{array}{c}\text { Large } \\
N=106\end{array}$ & $\begin{array}{c}\text { Small } \\
N=163\end{array}$ & $\begin{array}{c}\begin{array}{c}\text { Make-to-Order } \\
N=145\end{array} \\
\end{array}$ & $\begin{array}{c}\text { Make-to-Stock } \\
\quad N=92\end{array}$ \\
\hline Job rotation & & $\begin{array}{l}0.063 \\
\text { Mild }\end{array}$ & $\begin{array}{l}0.096 \\
\text { Strong }\end{array}$ & \\
\hline Managers' salaries based on company-wide performance & $\begin{array}{l}-0.061 \\
\text { Mild }\end{array}$ & & $\begin{array}{l}-0.093 \\
\text { Strong }\end{array}$ & \\
\hline \multicolumn{5}{|l|}{ Top management communication on the importance of working together } \\
\hline Managers fostering positive attitudes between departments & $\begin{array}{l}0.336 \\
\text { Strong }\end{array}$ & $\begin{array}{l}0.416 \\
\text { Strong }\end{array}$ & $\begin{array}{l}0.403 \\
\text { Strong }\end{array}$ & $\begin{array}{l}0.355 \\
\text { Strong }\end{array}$ \\
\hline Co-location & $\begin{array}{l}0.069 \\
\text { Strong } \\
\end{array}$ & & & $\begin{array}{l}0.092 \\
\text { Strong } \\
\end{array}$ \\
\hline Departments' joint accountability for results & $\begin{array}{l}0.112 \\
\text { Strong } \\
\end{array}$ & & & $\begin{array}{l}0.123 \\
\text { Strong } \\
\end{array}$ \\
\hline \multicolumn{5}{|l|}{ Employee incentives for customer satisfaction } \\
\hline Top management developing company-wide consensus on strategy & $\begin{array}{l}0.124 \\
\text { Strong }\end{array}$ & & & $\begin{array}{l}0.125 \\
\text { Strong } \\
\end{array}$ \\
\hline Top management fostering a culture of collaboration & & $\begin{array}{l}0.093 \\
\text { Mild }\end{array}$ & $\begin{array}{l}0.100 \\
\text { Mild }\end{array}$ & \\
\hline Employee-training regarding their own and other departments & $\begin{array}{l}0.182 \\
\text { Strong }\end{array}$ & & $\begin{array}{l}0.078 \\
\text { Mild }\end{array}$ & \\
\hline $\begin{array}{l}\text { Informal interactions (picnics, sports events) between employees across } \\
\text { departments }\end{array}$ & $\begin{array}{l}-0.075 \\
\text { Mild }\end{array}$ & & & \\
\hline Company-wide (ERP) computer system & & & & $\begin{array}{l}-0.234 \\
\text { Strong }\end{array}$ \\
\hline
\end{tabular}

Strong indicates a significance of $p<0.05$; Mild indicates $p<=0.10$; Entry is blank when $p>0.10$ 
Table 6. Summary of Multiple Regression Results

\begin{tabular}{|c|c|c|}
\hline $\begin{array}{l}\text { Strength } \\
\text { of support }\end{array}$ & Antecedent & Conclusion \\
\hline \multirow{5}{*}{ 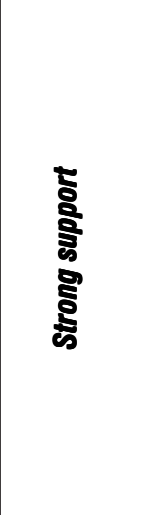 } & Job rotation & $\begin{array}{l}\text { There is evidence that job rotation enhances integration. It had a strong effect } \\
\text { on the coordination aspects of integration. }\end{array}$ \\
\hline & $\begin{array}{l}\text { Line managers' encouragement of positive attitudes } \\
\text { between departments }\end{array}$ & $\begin{array}{l}\text { Our results suggest that line managers' fostering of positive attitudes between } \\
\text { departments plays a strong role in internal supply chain integration. By far, this } \\
\text { was the best predictor of integration levels. The significance of this variable } \\
\text { was strong across all components of integration. }\end{array}$ \\
\hline & Co-location & $\begin{array}{l}\text { Employee co-location was found to be a strong predictor of integration, } \\
\text { particularly in large and make-to-stock company environments. }\end{array}$ \\
\hline & Joint accountability & $\begin{array}{l}\text { Our statistical analysis showed that holding disparate functional managers jointly } \\
\text { accountable for company goals had a strong effect on integration levels. This effect } \\
\text { was strong for larger companies and for companies with make-to-stock policies. }\end{array}$ \\
\hline & Company-wide consensus on strategy & $\begin{array}{l}\text { Developing a consensus on company strategy had a significant effect on } \\
\text { integration for the larger companies and companies with make-to-stock policies. }\end{array}$ \\
\hline \multirow{3}{*}{ 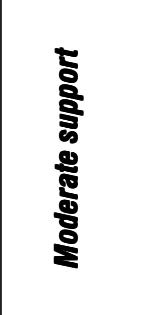 } & Employee training regarding other departments & $\begin{array}{l}\text { Training employees regarding other departments appears to be effective in } \\
\text { increasing integration, particularly in larger companies. }\end{array}$ \\
\hline & Top management fostering a culture of collaboration & $\begin{array}{l}\text { Emphasis by top management on a culture of collaboration appears to have only } \\
\text { a mild effect on integration. The small effect was seen for smaller companies } \\
\text { and for companies with make-to-order policies. }\end{array}$ \\
\hline & $\begin{array}{l}\text { Top management communication on the importance of } \\
\text { working together }\end{array}$ & $\begin{array}{l}\text { There was only a weak support for the hypothesis that the importance placed by } \\
\text { top management on integration will be reflected by the extent of integration in a } \\
\text { company. This was seen in the communications aspect of integration (Table 4). }\end{array}$ \\
\hline \multirow{4}{*}{ 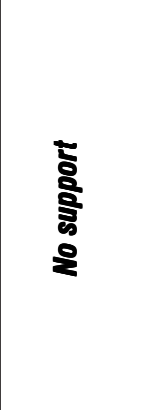 } & Performance incentives for managers & $\begin{array}{l}\text { We did not find any evidence for paying departmental managers incentives } \\
\text { based on company-wide performance in order to foster integration. There were } \\
\text { some negative results for this variable. }\end{array}$ \\
\hline & Employee incentives & $\begin{array}{l}\text { Rewarding employees for acting in the customers' interests did not raise the } \\
\text { level of internal supply chain integration in our analysis. }\end{array}$ \\
\hline & Informal interactions & $\begin{array}{l}\text { Our analysis suggests that informal interactions among disparate functional } \\
\text { groups had no statistically discernible effect on integration. There were some } \\
\text { negative results for this variable. }\end{array}$ \\
\hline & Enterprise-wide computer systems & $\begin{array}{l}\text { The impact of enterprise-wide computer systems on integration level was not } \\
\text { discernible. }\end{array}$ \\
\hline
\end{tabular}

(ANOVA) of each of the four regression models showed that all of the four models had a high significance $(p<0.001)$. Table 5 displays the significant regression coefficients and their significance levels. Each of the four columns to the right of Table 5 represents the result of a distinct multiple-regression analysis. For example, job rotation has a mild relationship to integration in small companies, but a strong relationship to integration in make-to-order companies.

The statistical analysis across different components of integration (Table 4) and across different subgroups (Table 5) are summarised in Table 6 showing the strength of support for each of the 12 hypotheses postulated in Section 2.

\section{Conclusions}

In this research our goal was to identify ways in which a company might nurture internal supply chain integration. We found the most effective interventions to be at the line manager's level. Line managers are able to improve integration by fostering a positive attitude for other departments. Integration appears also to be enhanced by making departments jointly accountable for achieving company goals. Additionally, at the employee level, integration may be enhanced by the related practices of co-locating, job rotation, and training employees about other departments. Further, at the top management level, the emphasis placed by top management on integration appears to foster integration. 
The contribution of this paper is in testing posited relationships between integration antecedents and integration levels. The antecedents or interventions were identified from previous literature, and 12 hypotheses were postulated that linked antecedents to integration levels. We carried out multiple regression on survey data to test the hypotheses. While some of the interventions espoused in the current literature are supported by this study as mentioned in the previous paragraph, our results question some other actions recommended strongly by current literature, as identified below.

Earlier studies have suggested that top management effort is crucial for the integration of internal functions. Respondents in (Daugherty et al., 1996) for example, placed top management support as the single most important factor for enhancing integration. However our study found only a moderate support for this notion. Similarly enterprise-wide computer systems (ERP) are also commonly accepted as a tool to achieve enterprise-wide integration (Gattiker, 2007; Davenport, 2000). Our study however, did not find any significant effect of ERP systems on internal supply chain integration.

An obvious avenue for further study is the effect of top management efforts on integration. The nature of these efforts and the type of firms where they are effective bears further scrutiny. Similarly the effect of ERP systems on internal integration needs to be studied further. Additionally, studies of the antecedents to integration could be carried out in larger economies such as the U.S. and developing countries like China or India. Comparisons of findings in these countries to the findings in this paper would provide further evidence of effective nurturing policies for managers.

This study, like other survey-based studies, has certain limitations. The sample for the survey was drawn from a database of New Zealand businesses, thus the results are generalizable only to the extent that these businesses resemble the population of all businesses. Much of the data reported here is also based on management perceptions. Previous research however, has shown these qualitative assessments to be reliable (see for example Dess and Robinson, 1984 and Venkatraman and Ramanujam, 1986). Finally, the term internal integration, as discussed in the opening paragraphs of this paper, is itself a potentially confusing term and might be interpreted quite differently across industry groups. These perceptions may have played a role in the answers provided on the survey and could potentially have impacted the findings here.

\section{Acknowledgements}

The constructive comments received from an anonymous referee are gratefully acknowledged.

\section{References}

Aggarwal, N. and Singh, R. (2004). Market Orientation in Indian Organizations: An Empirical Study. Marketing Intelligence and Planning, 22 (6/7), 700-710.

Barratt, M., and Barratt, R. (2011). Exploring internal and external supply chain linkages: Evidence from the field. Journal of Operations Management, 29(5), 514-528.

Calantone, R., Droge, C., and Vickery, S. (2002). Investigating the manufacturing-marketing interface in new product development: Does context affect the strength of relationships? Journal of Operations Management, 20(3), 273.

Chen, H., Mattioda, D. D. M., and Daugherty, P. J. (2007). Firmwide integration and firm performance. International Journal of Logistics Management, 18(1), 5.

Childerhouse, P., and Towill, D. (2011). Arcs of supply chain integration. International Journal of Production Research, 49(24), 7441.

Cousineau, M., Lauer, T.W., and Peacock, E. (2004). Supplier source integration in a large manufacturing company, Supply Chain Management, 9(1), 110-117.

Daugherty, P. J., Ellinger, A. E., and Gustin, C. M. (1996). Integrated logistics: achieving logistics performance improvements. Supply Chain Management, 1(3), 25.

Davenport, T., H. . (2000). Long live ERP. CIO, 13(10), 56.

Dess, G. G., and Robinson, R. B., Jr. (1984). Measuring Organizational Performance in the Absence of Objective Measures: The Case of the Privately-Held Firm and Conglomerate Business Unit. Strategic Management Journal, 5(3), 265.

Droge, C., Jayaram, J., and Vickery, S. K. (2004). The effects of internal versus external integration practices on time-based performance and overall firm performance. Journal of Operations Management, 22(6), 557-573.

Ellinger, A. E. (2000). Improving marketing/logistics crossfunctional collaborations in the supply chain. Industrial Marketing Management, 29(1), 85.

Ellinger, A. E., Keller, S. B., and Hansen, J. D. (2006). Bridging the divide between logistics and marketing: facilitating collaborative behavior. Journal of Business Logistics, 27(2), 1.

Flynn, B., Huo, B., and Zhao, X. (2010). The impact of supply chain integration on performance: A contingency and configuration approach. Journal of Operations Management, 28(1), 58. 
Gattiker, T. F. (2007). Enterprise resource planning (ERP) systems and the manufacturing-marketing interface: an information-processing theory view. International Journal of Production Research, 45(13), 2895-2917.

Giménez, C. (2004). Supply Chain Management Implementation in the Spanish Grocery Sector: An Exploratory Study. UPF Economics and Business Working Paper (No. 668). Barcelona: Universitat Pomepu Fabra.

Giménez, C., and Ventura, E. (2003). Supply chain management as a competitive advantage in the Spanish grocery sector. International Journal of Logistics Management, 14(1), 77.

Griffin, A., and Hauser, J. R. (1996). Integrating RandD and marketing: A review and analysis of the literature. The Journal of Product Innovation Management, 13(3), 191.

Hansen, M. T., and Nohria, N. (2004). How to Build Collaborative Advantage. MIT Sloan Management Review, 46(1), 22.

Hausman, W. H., Montgomery, D. B., and Roth, A. V. (2002). Why should marketing and manufacturing work together? Some exploratory empirical results. Journal of Operations Management, 20(3), 241.

Kahn, K. B. (1996). Interdepartmental integration: A definition with implications for product development performance. The Journal of Product Innovation Management, 13(2), 137.

Kahn, K. B., and Mentzer, J. T. (1994). Norms that distinguish between marketing and manufacturing. Journal of Business Research, 30(2), 111.

Kahn, K. B., and Mentzer, J. T. (1996). Logistics and interdepartmental integration. International Journal of Physical Distribution and Logistics Management, 26(8), 6.

Kahn, K. B., and Mentzer, J. T. (1998). Marketing's integration with other departments. Journal of Business Research, 42(1), 53.

Lambert, D.M., Cooper, M.C., and Pagh, J. (1998). Supply chain management: implementation issues and research opportunities. International Journal of Logistics Management, 19(2), 1-19.

Lawrence, P.R. and Lorsch, J.W. (1967), Organization and Environment: Managing Differentiation and Integration, Boston, MA: Graduate School of Business Administration, Harvard University.

Lunn, T. (1997). Breaking down silos and building teamwork. Hospital Materiel Management Quarterly, 19(2), 9.

Mollenkopf, D., Gibson, A., and Ozanne, L. (2000). The integration of marketing and logistics functions: An empirical examination of New Zealand firms. Journal of Business Logistics, 21(2), 89.

Murphy, P. R., and Poist, R. F. (1992). The logistics-marketing interface: Techniques for enhancing cooperation. Transportation Journal, 32(2), 14.

Narayanan, S., Jayaraman, V., Luo, Y., and Swaminathan, J. (2011). The antecedents of process integration in business process outsourcing and its effect on firm performance. Journal of Operations Management, 29(1/2), 3.

O'Leary-Kelly, S. W., and Flores, B. E. (2002). The integration of manufacturing and marketing/sales decisions: Impact on organizational performance. Journal of Operations Management, 20(3), 221.

Pagell, M. (2004). Understanding the factors that enable and inhibit the integration of operations, purchasing and logistics. Journal of Operations Management, 22(5), 459.

Soti, A., Shankar, R, and Kaushal, O.P. (2010). Modeling the enablers of six sigma using interpretive structural modeling, Journal of Modelling in Management, 5(2), 124133.

Stank, T. P., Daugherty, P. J., and Ellinger, A. E. (1999). Marketing/logistics integration and firm performance. International Journal of Logistics Management, 10(1), 11.

Stank, T. P., Keller, S. B., and Daugherty, P. J. (2001). Supply chain collaboration and logistical service performance. Journal of Business Logistics, 22(1), 29.

Stevens, G. C. (1989). Integrating the Supply Chain. International Journal of Physical Distribution and Materials Management, 19(8), 3.

van Hoek, R. I., and Mitchell, A. J. (2006). The challenge of internal misalignment. International Journal of Logistics Research and Applications: A Leading Journal of Supply Chain Management, 9(3), 269 - 281.

van Hoek, R., Ellinger, A. E., and Johnson, M. (2008). Great divides: internal alignment between logistics and peer functions. International Journal of Logistics Management, 19(2), 110.

Venkatraman, N., and Ramanujam, V. (1986). Measurement of Business Performance in Strategy Research: A Comparison of Approaches. The Academy of Management Review, 11(4), 801.

Wong, C., andand Boon-itt, S. (2011). The contingency effects of environmental uncertainty on the relationship between supply chain integration and operational performance. Journal of Operations Management, 29(6), 604

Chuda Basnet is an Associate Professor at the Waikato Management School, New Zealand. He has received a B.E. in Mechanical Engineering, a M.S. in Industrial and Management Engineering and a PhD in Industrial Engineering and Management. His research interests are in the areas of manufacturing modelling, supply chain management and decision support systems. He has previously published in Decision Support Systems, Journal of the Operational Research Society and Annals of Operations Research. 
Basnet and Wisner : Nurturing Internal Supply Chain Integration Operations \& Supply Chain Management 5 (1) pp 27-41 ๔ 2012

Joel Wisner earned his Ph.D. in Supply Chain Management from Arizona State University. He has written two supply chain management textbooks that currently enjoy a wide distribution among many universities offering supply chain management classes. His research interests are in quality assessment and improvement strategies along the supply chain. His articles have appeared in numerous journals including Journal of Business Logistics, Journal of Operations Management, Journal of Supply Chain Management, Journal of Transportation, Production and Operations Management Journal, and Quality Management Journal. 


\section{Appendix 1. Survey Instrument}

\section{Part A - Level of Internal Supply Chain Integration}

In this part we are interested in measuring aspects of internal integration in your company. Please circle the number that best reflects your views on the question at hand regarding your company.

In my company the departments involved in production, sales and distribution of products:

\begin{tabular}{|c|c|c|c|c|c|c|c|c|}
\hline & & $\begin{array}{l}\text { Strongly } \\
\text { Disagree }\end{array}$ & & & eut & & & $\begin{array}{c}\text { Strongly } \\
\text { Agree }\end{array}$ \\
\hline 1 & Share ideas, information, and resources between them. & 1 & 2 & 3 & 4 & 5 & 6 & 7 \\
\hline 2 & Conduct joint planning to anticipate and resolve supply chain problems. & 1 & 2 & 3 & 4 & 5 & 6 & 7 \\
\hline 3 & Spend time developing a mutual understanding of responsibilities. & 1 & 2 & 3 & 4 & 5 & 6 & 7 \\
\hline 4 & Strive to maintain a good working relationship with each other. & 1 & 2 & 3 & 4 & 5 & 6 & 7 \\
\hline 5 & Interact with each other through meetings or phones or emails. & 1 & 2 & 3 & 4 & 5 & 6 & 7 \\
\hline 6 & Interact with each other through the exchange of forms, reports, or documents. & 1 & 2 & 3 & 4 & 5 & 6 & 7 \\
\hline 7 & Spend time discussing future customer needs. & 1 & 2 & 3 & 4 & 5 & 6 & 7 \\
\hline 8 & Are quite accessible to each other. & 1 & 2 & 3 & 4 & 5 & 6 & 7 \\
\hline 9 & Share the same vision for the company. & 1 & 2 & 3 & 4 & 5 & 6 & 7 \\
\hline 10 & Establish joint objectives. & 1 & 2 & 3 & 4 & 5 & 6 & 7 \\
\hline 11 & Get along well with each other. & 1 & 2 & 3 & 4 & 5 & 6 & 7 \\
\hline 12 & Share information regarding own department with other departments. & 1 & 2 & 3 & 4 & 5 & 6 & 7 \\
\hline 13 & Consult with each other before making decisions affecting other departments. & 1 & 2 & 3 & 4 & 5 & 6 & 7 \\
\hline 14 & Work frequently in informal cross-departmental teams. & 1 & 2 & 3 & 4 & 5 & 6 & 7 \\
\hline 15 & Understand the pressures and concerns of each other. & 1 & 2 & 3 & 4 & 5 & 6 & 7 \\
\hline 16 & Synchronise their activities with each other. & 1 & 2 & 3 & 4 & 5 & 6 & 7 \\
\hline 17 & Work together for the benefit of the company. & 1 & 2 & 3 & 4 & 5 & 6 & 7 \\
\hline
\end{tabular}

\section{Part B - Management actions supporting integration}

In this part, we are interested in your opinion of management activities supporting internal supply chain integration. In my company:

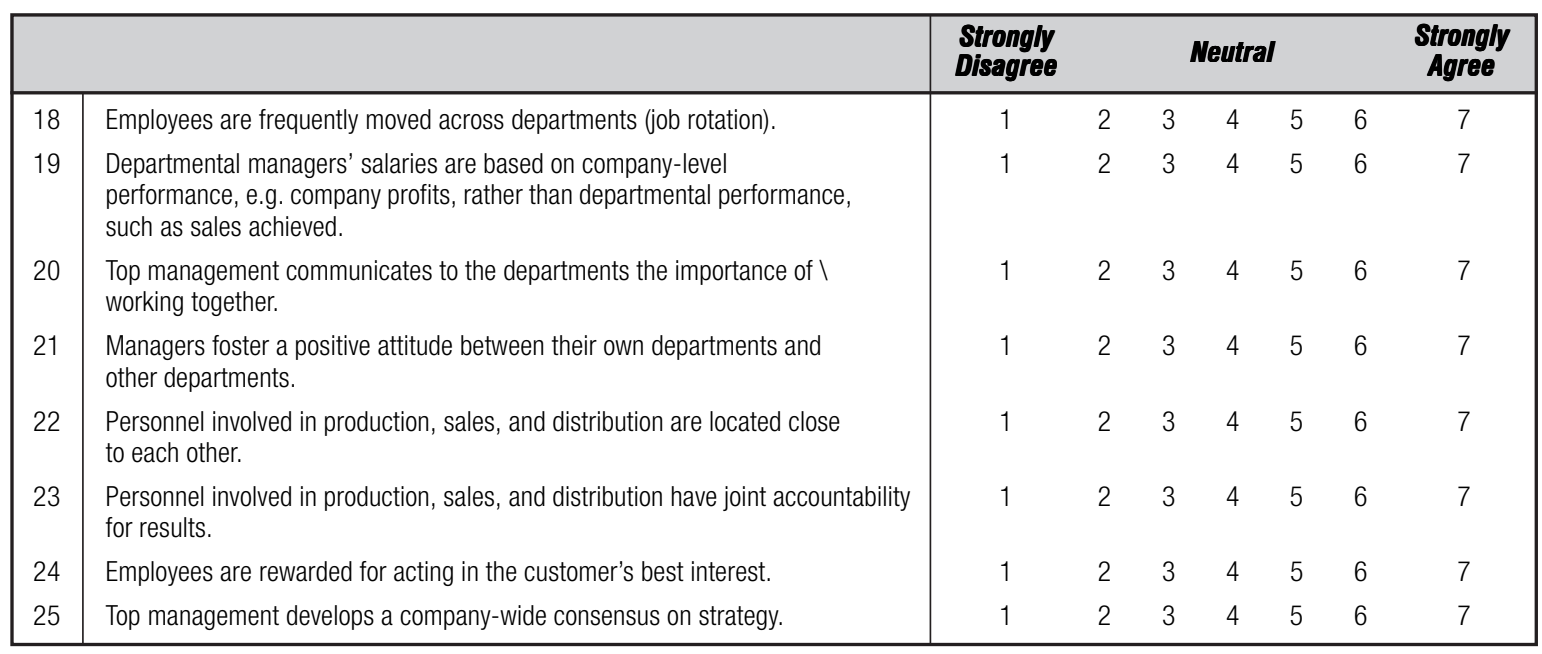

29. My company has implemented an enterprise-wide (ERP) computer system (e.g. SAP, Microsoft Dynamics, Baan, Peoplesoft, JD Edwards, etc.).

Please enter number of years since implementation: (Enter 0, if not implemented) 